\title{
Gene expression and biological processes influenced by deletion of Stat3 in pulmonary type II epithelial cells Yan $\mathrm{Xu}^{*}$, Machiko Ikegami, Yanhua Wang, Yohei Matsuzaki and Jeffrey A Whitsett
}

\author{
Address: Division of Pulmonary Biology, Cincinnati Children's Hospital Medical Center, Department of Pediatrics, University of Cincinnati \\ College of Medicine, 3333 Burnet Avenue, Cincinnati, OH, USA \\ Email: Yan Xu* - yan.xu@cchmc.org; Machiko Ikegami - machiko.ikegami@cchmc.org; Yanhua Wang - yanhua.wang@cchmc.org; \\ Yohei Matsuzaki - yohei.matsuzaki@cchmc.org; Jeffrey A Whitsett - jeff.whitsett@cchmc.org \\ * Corresponding author
}

Published: 10 December 2007

BMC Genomics 2007, 8:455 doi:10.1/86/147|-2164-8-455
Received: 8 May 2007

Accepted: 10 December 2007

This article is available from: http://www.biomedcentral.com/I47I-2/64/8/455

(c) 2007 Xu et al; licensee BioMed Central Ltd.

This is an Open Access article distributed under the terms of the Creative Commons Attribution License (http://creativecommons.org/licenses/by/2.0), which permits unrestricted use, distribution, and reproduction in any medium, provided the original work is properly cited.

\begin{abstract}
Background: The signal transducer and activator of transcription 3 (STAT3) mediates gene expression in response to numerous growth factors and cytokines, playing an important role in many cellular processes. To better understand the molecular mechanisms by which Stat 3 influences gene expression in the lung, the effect of pulmonary epithelial cell specific deletion of Stat3 on genome wide mRNA expression profiling was assessed. Differentially expressed genes were identified from Affymetrix Murine GeneChips analysis and subjected to gene ontology classification, promoter analysis, pathway mapping and literature mining.
\end{abstract}

Results: Total of 791 mRNAs were significantly increased and 314 mRNAs were decreased in response to the deletion of Stat $3^{\Delta / \Delta}$ in the lung. STAT is the most enriched cis-elements in the promoter regions of those differentially expressed genes. Deletion of Stat3 induced genes influencing protein metabolism, transport, chemotaxis and apoptosis and decreased the expression of genes mediating lipid synthesis and metabolism. Expression of SrebfI and 2, genes encoding key regulators of fatty acid and steroid biosynthesis, was decreased in type II cells from the Stat3 $3 / \Delta$ mice, consistent with the observation that lung surfactant phospholipids content was decreased. Stat 3 influenced both pro- and anti-apoptotic pathways that determine cell death or survival. Akt, a potential transcriptional target of Stat3, was identified as an important participant in Stat3 mediated pathways including Jak-Stat signaling, apoptosis, Mapk signaling, cholesterol and fatty acid biosynthesis.

Conclusion: Deletion of Stat3 from type II epithelial cells altered the expression of genes regulating diverse cellular processes, including cell growth, apoptosis and lipid metabolism. Pathway analysis indicates that STAT3 regulates cellular homeostasis through a complex regulatory network that likely enhances alveolar epithelial cell survival and surfactant/lipid synthesis, necessary for the protection of the lung during injury. 


\section{Background}

The signal transducers and activators of transcription (STATs) were initially identified as a family of latent cytoplasmic transcription factors that are activated by various cytokines, growth factors and other stimuli, and phosphorylated by many protein kinases [1-4]. In response to various stimuli, STAT family members are phosphorylated by receptor associated kinases, form homo- or heterodimers and are translocated to the cell nucleus where they activate transcription [5]. Recent studies also support the role of unphosphorylated STAT3 that accumulates in nucleus and activates transcription by binding to NFkappaB [6]. STAT3 regulates a variety of biological processes, functioning at both transcriptional and non-transcriptional levels to influence cell growth, survival and metabolism. Its capacity to induce cell transformation and tumorigenesis makes it a potential therapeutic target for various cancers $[7,8]$.

Systemic deletion of Stat3 is embryonic lethal in the mouse, indicating its important role in embryogenesis [9]. Biological roles of STAT3 in various organs and cells have been studied in vitro as well as cell specific deletion in the mouse in vivo. The biological consequences of Stat3 deletion are surprisingly diverse and sometimes contradictory. For example, cardiomyocyte-specific STAT3 deficiency caused cardiac fibrosis and heart dysfunction with advanced age [10]. Hepatic cell specific deletion of Stat3 caused insulin resistance associated with increased expression of gluconeogenic genes [11]. Conditional ablation of Stat3 in respiratory epithelium of the mouse (Stat $3^{\Delta / \Delta}$ mice) did not alter lung morphogenesis or function but enhanced susceptibility to hyperoxia and adenoviral induced lung injury whereas overexpression of Stat3C (a constitutive active form of STAT3) in pulmonary epithelium protects against hyperoxic lung injury, suggesting that STAT3 is required for the maintenance of surfactant homeostasis and lung function during injury [12-14]. While STAT3 has been proposed as an anti-apoptotic protein through the induction of survival genes such as $\mathrm{Bcl} 2$ like $1(\mathrm{Bcl}-\mathrm{X})$ and B-cell leukemia/lymphoma 2 (Bcl-2), STAT3 also exerts pro-apoptotic effect through the regulation of insulin-like growth factor binding protein 5 (IGFBP-5) to modulate mammary epithelial apoptosis $[4,15]$. STAT3 is abundantly and ubiquitously expressed in many tissues and distributed between the cell cytosol and nucleus. A direct effect of non-phosphorylated, cytoplasmic STAT3 on cell motility was reported recently through direct protein-protein interactions [16], indicating a non-transcriptional function of STAT3.

The functions of STAT3 vary in different cellular and physiologic contexts, influencing diverse gene targets by interaction with other proteins and genes. The diversity of STAT3 functions indicate that STAT3 is involved in com- plex genetic networks to maintain cellular homeostasis rather serving a singular role in acute phase responses as initially defined. In the present study, we sought to systemically study the role of STAT3 in pulmonary epithelial cell homeostasis. Using knowledge based gene expression profiling approaches and a conditional system that selectively deleted Stat3 in the respiratory epithelium; we identified a large STAT3-dependent network that influences a wide variety of biological processes in type II alveolar cells in the lung.

\section{Results and Discussion Identification of differentially expressed genes in alveolar type II epithelial cells from Stat ${ }^{\Delta / \Delta}$ mice}

In previous studies Stat 3 mRNA and protein expression were markedly reduced in Type II cells isolated from Stat $3^{\Delta / \Delta}$ mice, being less than $10 \%$ of control levels [12]. To identify the RNAs influenced by the conditional deletion of Stat3 $3^{\Delta / \Delta}$, RNAs isolated from alveolar epithelial type II cells of control and Stat $3^{\Delta / \Delta}$ mice were compared using Affymetrix murine genome MOE430 gene chips. The complete dataset can be found at Gene Expression Omnibus (GEO) [17]; Accession no. GSE6846. Total of 1105 genes were identified as significantly altered using the criteria described in Method. Among them, 791 mRNAs were increased and 314 mRNAs were decreased in response to the deletion of $S t a t 3^{\Delta / \Delta}$ in the lung (Additional file 1). Changes in mRNA expression of a subset of genes including Malt1, Rnt4, Reg3g, Bcl2l1, Cds2, Cdipt, Fasn, Acox2, Akt2, Gpam, Foxj1, Abca3, Srebf1, Srebf2 and Scap were validated by real-time RT-PCR. Genes cross validated by RT-PCR are listed in Table 1 and indicated by asterisks $\left({ }^{*}\right)$ in Additional file 1.

\section{Functional classification of differentially expressed genes revealed the dysregulation of various biological processes in type II epithelial cells from Stat3 ${ }^{\Delta / \Delta}$ mice}

Differentially expressed genes were classified according to Gene Ontology (GO) classification on Biological Process. The Fisher Exact Test was used to calculate the probability of each category that was overrepresented in the selected list using the entire MOE430 mouse genome as reference dataset. Deletion of Stat 3 from type II cells significantly induced the genes involved in protein metabolism, protein transport, chemotaxis and apoptosis and decreased the expression of genes in lipid synthesis and metabolism (Table 2).

\section{Promoter analysis identified putative common regulators of the differentially expressed genes}

To identify putative common transcription factors regulating the type II cell responses to Stat3 deletion, promoter region ( $-2 \mathrm{~kb}$ to exon 1$)$ of differentially expressed genes were searched for overrepresented cis-elements using MatInspector (Genomatix) vertebrate matrix library. In com- 
Table I: Comparison of mRNAs by RT-PCR and RNA microarray

\begin{tabular}{lrrrl}
\hline \multicolumn{1}{c}{ GENE } & RT-PCR & Microarray & P-Value for RT-PCR & Gene Name \\
\hline Maltl & 3.5 & 6.27 & $<0.050$ & Mucosa associated lymphoid tissue lymphoma translocation gene I \\
Rtn4 & 2.7 & 4.86 & $<0.050$ & reticulon 4 \\
Reg3g & -5.5 & -6.02 & $<0.050$ regenerating islet-derived 3 gamma \\
Bcl2II & -1.2 & -1.54 & 0.053 Bcl2-like I \\
Akt2 & -1.5 & -1.58 & $<0.050$ thymoma viral proto-oncogene 2 \\
Abca3 & -2.4 & -1.59 & $<0.050$ & ATP-binding cassette, sub-family A (ABCI), member 3 \\
Scap & -1.4 & -1.58 & $<0.050$ SREBP cleavage activating protein \\
Srebfl & -1.4 & -1.69 & $<0.050$ & sterol regulatory element binding factor I \\
Srebf2 & -1.3 & -1.50 & 0.080 & sterol regulatory element binding factor 2 \\
Cdipt & -1.8 & -1.54 & $<0.001$ & CDP-diacylglycerol--inositol 3-phosphatidyltransferase \\
Fasn & -1.7 & -1.57 & $<0.001$ & fatty acid synthase \\
Acox2 & -1.5 & -1.67 & $<0.001$ & acyl-Coenzyme A oxidase 2 \\
Cds2 & -2.1 & -1.78 & $<0.001$ & CDP-diacylglycerol synthase (phosphatidate cytidylyltransferase) \\
Gpam & -1.5 & -1.54 & $<0.001$ & glycerol-3-phosphate acyltransferase \\
\hline
\end{tabular}

Note: Fold change of mRNA in Stat $3^{\Delta / \Delta}$ mice to control is shown.

pare with the sequence of random chosen gene promoters, the cis-elements significantly enriched in the promoter region of differentially expressed genes were selected based on a binomial probability calculation and their percentage frequency in our selected gene list
(Adjusted p Value $<0.001$ and frequency $>50 \%$ ). STAT, EGRF, AHRR, SP1F, ZF5F, E2FF, HIFF, SREB and AP2F were the most overrepresented cis-elements and may therefore mediate changes in gene expression in cells from Stat $3^{\Delta / \Delta}$ mice (Table 3 ). The finding that STAT was the

Table 2: Functional Classification of Genes Differentially Expressed in Stat3 ${ }^{\Delta / \Delta}$ mice

\begin{tabular}{|c|c|c|c|}
\hline \multicolumn{4}{|c|}{ GO Classification of Genes Up-regulated in Stat $3^{\Delta / \Delta}$ mice } \\
\hline Term & Count & $\%$ & PValue \\
\hline Biopolymer modification & 115 & 13.94 & $7.30 \mathrm{E}-13$ \\
\hline Cellular protein metabolism & 164 & 19.88 & $5.83 \mathrm{E}-10$ \\
\hline Protein transport & 52 & 6.30 & 2.49E-07 \\
\hline Phosphate metabolism & 62 & 7.52 & $3.3 \mathrm{IE}-07$ \\
\hline Chemotaxis & 17 & 2.06 & I.38E-06 \\
\hline Protein kinase cascade & 24 & 2.91 & 6.83E-06 \\
\hline Apoptosis & 40 & 4.85 & I.69E-05 \\
\hline Regulation of apoptosis & 29 & 3.52 & 4.93E-05 \\
\hline Positive regulation of cellular metabolism & 25 & 3.03 & $9.95 \mathrm{E}-05$ \\
\hline Cell migration & 19 & 2.30 & $2.26 \mathrm{E}-03$ \\
\hline Transcription & 106 & 12.85 & 2.64E-03 \\
\hline \multicolumn{4}{|c|}{ GO Classification of Genes Down-regulated in Stat $3^{\Delta / \Delta}$ mice } \\
\hline Term & Count & $\%$ & PValue \\
\hline Cellular lipid metabolism & 33 & 9.97 & $3.60 \mathrm{E}-13$ \\
\hline Lipid biosynthesis & 21 & 6.34 & $3.59 \mathrm{E}-\mathrm{II}$ \\
\hline Sterol metabolism & 10 & 3.02 & $2.96 \mathrm{E}-07$ \\
\hline Fatty acid metabolism & 14 & 4.23 & $5.35 \mathrm{E}-07$ \\
\hline Steroid metabolism & 12 & 3.63 & $6.83 E-06$ \\
\hline Carboxylic acid metabolism & 18 & 5.44 & $5.84 \mathrm{E}-04$ \\
\hline Coenzyme metabolism & 10 & 3.02 & $2.5 \mathrm{IE}-03$ \\
\hline Cellular carbohydrate metabolism & 12 & 3.63 & $3.98 \mathrm{E}-03$ \\
\hline Electron transport & 14 & 4.23 & $2.64 \mathrm{E}-02$ \\
\hline Phosphate metabolism & 21 & 6.34 & 3.27E-02 \\
\hline
\end{tabular}

Note: Gene Ontology Analysis was preformed using public available web-based tool DAVID [8I]. Overrepresented biological processes were selected at the threshold of Fisher Exact Test $\mathrm{P}-\mathrm{V}$ alue $\leq 0.05$ and minimum gene counts belonging to an annotation term $\geq 2 \%$. 
Table 3: Enriched TFBS In Genes Differentially Expressed in Stat3 ${ }^{\Delta / \Delta}$ mice

\begin{tabular}{lcccccc}
\hline TFBS & Count (Diff_Gene) & $\begin{array}{c}\text { Frequency } \\
\text { (Diff_Gene) }\end{array}$ & Count (background) & $\begin{array}{c}\text { Frequency } \\
\text { (background) }\end{array}$ & P-Value & Q-Value \\
\hline V\$STAT & 863 & 0.97 & 786 & 0.79 & $4.93 \mathrm{E}-59$ & $2.29 \mathrm{E}-56$ \\
V\$EGRF & 850 & 0.96 & 757 & 0.76 & $2.92 \mathrm{E}-57$ & $1.35 \mathrm{E}-54$ \\
V\$AHRR & 706 & 0.80 & 544 & 0.54 & $4.04 \mathrm{E}-53$ & $1.87 \mathrm{E}-50$ \\
V\$SPIF & 857 & 0.97 & 789 & 0.79 & $2.15 \mathrm{E}-49$ & $9.96 \mathrm{E}-47$ \\
V\$ZF5F & 502 & 0.57 & 321 & 0.32 & $2.18 \mathrm{E}-48$ & $1.01 \mathrm{E}-45$ \\
V\$E2FF & 850 & 0.96 & 778 & 0.78 & $1.30 \mathrm{E}-47$ & $6.03 \mathrm{E}-45$ \\
V\$HIFF & 564 & 0.64 & 439 & 0.44 & $4.66 \mathrm{E}-30$ & $2.16 \mathrm{E}-27$ \\
V\$SREB & 513 & 0.58 & 425 & 0.42 & $2.76 \mathrm{E}-17$ & $1.28 \mathrm{E}-14$ \\
V\$AP2F & 492 & 0.56 & 420 & 0.42 & $4.93 \mathrm{E}-15$ & $2.29 \mathrm{E}-12$ \\
\hline
\end{tabular}

Note: promoter sequence (-2000 - 0 bps) from 886 out of II 05 differentially genes were available for analysis. The P-Value is calculated using binomial distribution probability. 5 random sets of 1000 mouse gene $-2 \mathrm{~kb}$ promoter regions were used to calculate the background frequency. The $\mathrm{Q}-\mathrm{V}$ alue is calculated using single-step Bonferroni adjustment to control for the multiple comparison effect.

most enriched cis-elements indicated the identification of a sub-group of potential direct transcriptional targets of Stat3 in lung epithelial cells. Sterol regulatory element binding factors (Srebf1 and 2, known as important transcriptional regulators of fatty acid and steroid biosynthesis), were significantly decreased in Stat $3^{\Delta / \Delta}$ mice. The SREB binding site was overrepresented in differentially expressed genes indicating that it is a potential regulator of the lipid metabolism pathways altered in $S t a t 3^{\Delta / \Delta}$ mice. Other significantly enriched TFBS include SP1F and HIFF. STAT3 and SP1 function cooperatively to activate the C/ EBP promoter, the SP1 site being required for IL-6 induction and transactivation by STAT3 [18]. HIF1A, SP1, SMAD3 AND SMAD4 can form multifactor complex, regulating VEGF and erythropoietin gene transcription through functional cooperation and association [19-21]. Consistent with the promoter analyses and literature findings, the mRNA expression of Klf5 (a member of the SP1 family) and Hif1a, Smad3 and Smad4 was simultaneously increased by Stat3 deletion, indicating the potential transcriptional complex formation among the corresponding transcription factors.

\section{Pathway analysis revealed known and novel functions of STAT3 in the lung}

Pathway enrichment test is an unbiased way to answer the question, "Are the differentially expressed genes enriched in certain pathways?" To address this issue, we compared the overlap of differentially expressed genes in Stat $3^{\Delta / \Delta}$ mice with the known biological pathways in KEGG (Kyoto Encyclopedia of Genes and Genomes) using 1) the mouse genome and 2) a list of genes shown to be least changed in response to the Stat 3 deletion in the gene array as background. Results from both analyses were consistent. Jak-Stat Signaling Pathway, Apoptosis, CytokineCytokine Receptor Interaction, Insulin Signaling Pathway, Mapk Signaling Pathway, Focal Adhesion, and Wnt Signaling Pathway were among the most enriched pathways identified from the analysis of differentially expressed genes (Table 4). mRNAs mediating steroid biosynthesis and fatty acid metabolism were mostly decreased in Stat $3^{\Delta / \Delta}$ mice. The most overrepresented pathways and the differentially expressed genes associated with those pathways are illustrated in Additional files 2. The finding that known Stat3 functions, including the Jak-Stat Signaling Pathway were identified from microarray analysis of Stat $3^{\Delta / \Delta}$ mice type II cells using knowledge integration approaches provides support for the utility of the analysis to detect novel pathways regulated by Stat3.

\section{Stat3 influences protein metabolism in lung type II cells}

"Protein metabolism" was the most enriched biological process $(5.83 \mathrm{E}-10)$, accounting for $20 \%$ of the induced genes caused by the deletion of Stat3. More than 40 genes encoding proteins involved in protein ubiquitination/ ubiquitin cycle were present (Table 5). Of interest, Casitas B-lineage lymphoma b (Cblb) was increased 7.3 fold. CBLB is a member of Cbl ubiquitin ligases (E3) protein family that are tyrosine-phosphorylated in response to a

Table 4: Enriched Pathways In Genes Differentially Expressed in Stat3 $^{\Delta / \Delta}$ mice

\begin{tabular}{lccc}
\hline \multicolumn{1}{c}{ Term } & Count & $\%$ & P-Value \\
\hline Jak-Stat Signaling Pathway & 38 & 3.26 & $7.56 \mathrm{E}-09$ \\
Apoptosis & 24 & 2.06 & $5.04 \mathrm{E}-06$ \\
Cytokine-Cytokine Receptor Interaction & 43 & 3.69 & $2.59 \mathrm{E}-05$ \\
Insulin Signaling Pathway & 28 & 2.40 & $5.53 \mathrm{E}-05$ \\
Mapk Signaling Pathway & 45 & 3.86 & $8.5 \mathrm{IE}-05$ \\
Focal Adhesion & 37 & 3.17 & $1.55 \mathrm{E}-04$ \\
Wnt Signaling Pathway & 28 & 2.40 & I.68E-04 \\
\hline
\end{tabular}

Overrepresented pathways were identified by comparison the overlap of differentially expressed genes and all genes in MOE430 mouse genome (reference) with the known KEGG pathways. A pathway is considered to be over-represented when a probability P-Value $\leq 0.0$ I and gene frequency (genes in the pathway/total number of differentially expressed genes) $\geq 2 \%$. 
Table 5: Genes In Ubiquitin Cycle Were Largely Induced In Stat3 ${ }^{\Delta / \Delta}$ Mice

\begin{tabular}{|c|c|c|c|c|}
\hline UniGene ID & Fold & P-Value & Gene Symbol & Gene Title \\
\hline Mm.328206 & 7.29 & $9.98 \mathrm{E}-04$ & Cblb & Casitas B-lineage lymphoma b \\
\hline Mm.260635 & 4.56 & $6.34 \mathrm{E}-03$ & Axot & Axotrophin \\
\hline Mm.98668 & 3.79 & $6.93 \mathrm{E}-05$ & Nedd4l & neural precursor cell expressed, developmentally down-regulated gene 4-like \\
\hline Mm.276229 & 3.37 & I.4IE-03 & Fbxo30 & F-box protein 30 \\
\hline Mm.258476 & 3.30 & $6.58 \mathrm{E}-03$ & Tbllx & transducin (beta)-like I X-linked \\
\hline Mm.28017 & 3.22 & $3.62 \mathrm{E}-03$ & Fbxwll & F-box and WD-40 domain protein II \\
\hline Mm. 16974 & 3.03 & I.66E-04 & Usp47 & ubiquitin specific peptidase 47 \\
\hline Mm.388965 & 3.01 & 8.38E-04 & Rnfl2 & Ring finger protein 12 \\
\hline Mm.4I7II & 2.87 & I.43E-03 & $\mathrm{Pja2}$ & Praja 2, RING-H2 motif containing (Pja2), transcript variant 2 , mRNA \\
\hline Mm.214746 & 2.75 & I.78E-03 & $\mathrm{Fbx} \times 3$ & F-box and leucine-rich repeat protein 3 \\
\hline Mm.242646 & 2.75 & I.83E-03 & Usp9x & ubiquitin specific protease $9, \mathrm{X}$ chromosome \\
\hline Mm.9002 & 2.70 & $6.26 \mathrm{E}-04$ & Ube3a & ubiquitin protein ligase E3A \\
\hline Mm.3005I & 2.53 & 4.86E-04 & RnflO & Ring finger protein 10 \\
\hline Mm.362II8 & 2.41 & $9.26 \mathrm{E}-04$ & Sumol & SMT3 suppressor of mif two 3 homolog I (yeast) (Sumol) \\
\hline Mm.328I35 & 2.36 & 3.35E-04 & Rfwd2 & Constitutive photomorphogenic protein (Copl) \\
\hline Mm.290908 & 2.34 & 3.27E-04 & Birc6 & baculoviral IAP repeat-containing 6 \\
\hline Mm. 180052 & 2.34 & 4.84E-03 & Ube2d2 & Ubiquitin-conjugating enzyme E2D 2 \\
\hline Mm.39160I & 2.29 & $9.75 \mathrm{E}-03$ & Ube2d3 & ubiquitin-conjugating enzyme E2D 3 \\
\hline Mm.4480 & 2.25 & I.28E-03 & Rbbp6 & Retinoblastoma binding protein 6 (Rbbp6) \\
\hline$M m .319512$ & 2.24 & $5.65 \mathrm{E}-03$ & Hip2 & huntingtin interacting protein 2 \\
\hline Mm. 12665 & 2.19 & I.60E-02 & Cul3 & cullin 3 \\
\hline Mm.244I79 & 2.12 & $3.75 \mathrm{E}-03$ & Hercl & $\begin{array}{l}\text { Hect (homologous to the E6-AP (UBE3A) carboxyl terminus) domain and RCCI } \\
(\mathrm{CHCl} \text { )-like domain (RLD) I }\end{array}$ \\
\hline Mm.392272 & 2.10 & $4.55 \mathrm{E}-04$ & Smurf2 & SMAD specific E3 ubiquitin protein ligase 2 \\
\hline Mm.29743I & 1.95 & 2.84E-03 & Senp2 & SUMO/sentrin specific peptidase 2 \\
\hline Mm.253542 & 1.94 & $1.53 \mathrm{E}-02$ & Rnfl 38 & ring finger protein 138 \\
\hline Mm.235407 & 1.94 & I.32E-02 & Ube2v2 & ubiquitin-conjugating enzyme E2 variant 2 \\
\hline Mm.392862 & 1.93 & $3.54 \mathrm{E}-03$ & Arih I & ariadne ubiquitin-conjugating enzyme E2 binding protein homolog \\
\hline Mm.783I2 & 1.89 & I.07E-02 & Wwpl & WW domain containing E3 ubiquitin protein ligase I \\
\hline Mm.44876 & 1.84 & $3.88 \mathrm{E}-03$ & Trim2 & tripartite motif protein 2 \\
\hline
\end{tabular}

wide variety of receptor mediated stimuli, including epidermal growth factor receptors, cytokine receptors such as colony stimulating factor family receptors (increased 2-3 fold in the $S t a t 3^{\Delta / \Delta}$ cells) and immune complex receptors such as Fcgr2b (increased 2.7 fold). CBLB functions as an adaptor protein that regulates many signal-transduction pathways including JAK-STAT signaling pathways through its ability to interact with critical signaling molecules [22]. The expression of genes encoding known CBLB binding partners was significantly increased in type II cells from the Stat $3^{\Delta / \Delta}$ mice, including SYK kinase (increased 4 fold), JAK2 (increased 2.1 fold), PKC (increased 2.6 fold), phosphatidylinositol 3-kinase (Pik3r1 increased 1.8 fold, Pik3c2a increased 3 fold), adenylate cyclase-associated protein 1 (Cap1 increased 5 fold) and Crk (increased 2.5 fold). These signaling molecules can in turn modulate various down stream signaling cascades including those mediated by small G-proteins (multiple members of RAS oncogene family were induced $2-3$ fold), as well as PI3K/ AKT mediated signaling and Nfat induction (increased 4.1 fold) [23-27]. CBLB physically interacts with another ubiquitin-protein ligase, NEDD4 (increased 3.8 fold), an interaction that reverses CBLB effects by targeting CBLB for ubiquitination and proteasomal degradation [28]. SLIM is a known E3 ubiquitin ligase specifically interacts with activated STAT1 and STAT4, inducing their ubiquitination and degradation [29]. We speculate that CBLB may act in a similar manner to regulate STAT3 signaling. In addition, SUMO1 and SUMO1 specific peptidase 2 were both increased more than 2 fold in Stat $3^{\Delta / \Delta}$ mice. SUMO1 can covalently modify many targets including STAT1 and glucocorticoid receptor NR3C1 (increased 5 fold) and regulate protein stability and transcriptional activity [30]. Taken together, deletion of STAT3 activates a number of molecules regulating protein metabolism, stability and routing, indicating the potential role of ubiquitination and sumoylation in cytokine signaling and STAT3 activation that influences cellular adaptation.

\section{STAT3 influences phosphate metabolism and protein kinase cascade in lung type II cells}

Expression of genes regulating "Phosphate metabolism" and "protein kinase cascade" were significantly increased in $\operatorname{Stat}^{\Delta / \Delta}$ mice (3.1E-07 and $1.38 \mathrm{E}-06$, respectively), accounting for $7.5 \%$ of total induced genes (Table 6 ). Expression of genes encoding a number of kinase that 
Table 6: Genes In Phosphate Metabolism Were Largely Induced In Stat3 ${ }^{\Delta / \Delta}$ Mice

\begin{tabular}{|c|c|c|c|c|}
\hline UniGene ID & Fold & P-Value & Gene Symbol & Gene Title \\
\hline Mm. 188734 & 8.32 & 3.47E-05 & Adk & Adenosine kinase \\
\hline Mm.2I495 & 4.70 & I.82E-03 & Mapk8 & Mitogen activated protein kinase 8 \\
\hline Mm.3879 & 4.69 & 4.29E-05 & Hifla & Hypoxia inducible factor I, alpha subunit \\
\hline Mm.86844 & 4.18 & I.89E-03 & Met & Met proto-oncogene \\
\hline Mm.225505 & 4.09 & $2.32 \mathrm{E}-03$ & Chka & Choline kinase alpha \\
\hline Mm.37503I & 4.02 & I.39E-03 & Syk & Spleen tyrosine kinase \\
\hline Mm.32759I & 3.60 & I.26E-03 & Cask & Calcium/calmodulin-dependent serine protein kinase \\
\hline Mm.248647 & 3.42 & $2.36 \mathrm{E}-02$ & $\mathrm{Pi} 4 \mathrm{k} 2 \mathrm{~b}$ & Phosphatidylinositol 4-kinase type 2 beta \\
\hline Mm.255822 & 3.31 & $2.08 \mathrm{E}-04$ & Camk2d & Calcium/calmodulin-dependent protein kinase II, delta \\
\hline Mm.25559 & 3.30 & 7.4IE-03 & Stk I7b & Serine/threonine kinase I7b (apoptosis-inducing) \\
\hline Mm.328476 & 3.15 & I.45E-02 & Rps6ka3 & Ribosomal protein S6 kinase polypeptide 3 \\
\hline Mm.289657 & 3.14 & I.66E-04 & Jakl & Janus kinase I \\
\hline Mm.3810 & 3.08 & 7.64E-03 & Pik3c2a & Phosphatidylinositol 3-kinase, C2 domain \\
\hline Mm.202606 & 3.04 & I.02E-04 & Mast4 & Microtubule associated serine/threonine kinase family member 4 \\
\hline Mm.309867 & 2.88 & 3.93E-04 & Ptk9 & Protein tyrosine kinase 9 \\
\hline Mm.280I25 & 2.86 & $3.15 \mathrm{E}-03$ & Crk & v-crk sarcoma virus CTIO oncogene homolog (avian) \\
\hline Mm.272548 & 2.82 & 4.37E-04 & Etnkl & Ethanolamine kinase I \\
\hline Mm. 197552 & 2.74 & I.IOE-03 & Tgfbrl & Transforming growth factor, beta receptor I \\
\hline Mm.262330 & 2.66 & I.54E-02 & Stk3 & Serine/threonine kinase 3 (Ste20, yeast homolog) \\
\hline Mm.295263 & 2.65 & I.43E-03 & Dcamkll & Double cortin and calcium/calmodulin-dependent protein kinase-like I \\
\hline Mm.222I 78 & 2.57 & $2.58 \mathrm{E}-04$ & Prkca & Protein kinase C, alpha (Prkca), mRNA \\
\hline Mm.310973 & 2.56 & $5.12 \mathrm{E}-04$ & Dyrkla & Dual-specificity tyrosine-(Y)-phosphorylation regulated kinase Ia \\
\hline Mm.3I3594 & 2.50 & $5.58 \mathrm{E}-03$ & Mpp5 & Palmitoylated 5 (MAGUK p55 subfamily member 5) \\
\hline Mm.6710 & 2.49 & $3.65 \mathrm{E}-02$ & Rockl & Rho-associated coiled-coil forming kinase I \\
\hline Mm.440470 & 2.46 & $3.16 \mathrm{E}-03$ & Crk7 & CDC2-related kinase 7 \\
\hline Mm.38906I & 2.36 & I.34E-03 & Pftkl & PFTAIRE protein kinase I (Pftk I), mRNA \\
\hline Mm.244236 & 2.34 & $8.50 \mathrm{E}-03$ & Pkn2 & Protein kinase N2 \\
\hline Mm.288I4I & 2.25 & 7.64E-03 & $\mathrm{Rp} 2 \mathrm{~h}$ & Retinitis pigmentosa 2 homolog (human) \\
\hline Mm.31672 & 2.21 & 4.65E-04 & Cdk6 & Cyclin-dependent kinase 6 (Cdk6), mRNA \\
\hline Mm.2I5I7I & 2.20 & $5.62 \mathrm{E}-04$ & Trpm6 & Transient receptor potential cation channel, subfamily M, member 6 \\
\hline Mm.3994 & 2.18 & $3.98 \mathrm{E}-04$ & Dusp 16 & Dual specificity phosphatase 16 \\
\hline Mm. I365II & 2.17 & $5.10 \mathrm{E}-04$ & TIkl & MKIAAOI 37 protein \\
\hline Mm.332231 & 2.16 & 3.0IE-03 & Magi2 & Membrane associated guanylate kinase, WW and PDZ domain containing 2 \\
\hline Mm. 16340 & 2.13 & I.50E-02 & Fgfr2 & Fibroblast growth factor receptor 2 \\
\hline Mm.275839 & 2.13 & I.00E-02 & Jak2 & Janus kinase 2 \\
\hline Mm.393II4 & 2.08 & $7.62 \mathrm{E}-04$ & Csnklal & Casein kinase I, alpha I \\
\hline Mm. 17918 & 2.08 & 7.94E-04 & MarcksII & MARCKS-like I \\
\hline Mm.368668 & 2.06 & $6.49 \mathrm{E}-04$ & Csnklg3 & Casein kinase I, gamma 3 (Csnklg3), mRNA \\
\hline Mm.291936 & 2.01 & $8.02 \mathrm{E}-03$ & Map4k5 & Mitogen-activated protein kinase kinase kinase kinase 5 \\
\hline Mm.35290 & -2.00 & I.42E-02 & Ripk4 & Receptor-interacting serine-threonine kinase 4 \\
\hline Mm.36006 & -2.39 & I.22E-03 & Ak7 & Adenylate kinase 7 \\
\hline Mm.306I63 & -2.68 & $8.63 \mathrm{E}-03$ & Prkarlb & Protein kinase, cAMP dependent regulatory, type I beta \\
\hline Mm.7373 & $-2.7 \mid$ & I.05E-03 & Perl & Period homolog I (Drosophila) \\
\hline Mm.3283I & -2.96 & 2.47E-02 & Wifl & Wnt inhibitory factor I \\
\hline Mm.44442 & -3.76 & $2.45 \mathrm{E}-04$ & Kndcl & Kinase non-catalytic C-lobe domain (KIND) containing I \\
\hline
\end{tabular}

phosphorylate STAT3 in vivo or in vitro were increased [31-35], including Janus kinase 1 and 2 (increased 3.1 and 2.6 fold, respectively), ribosomal protein S6 kinase polypeptide 3 (Rps6ka3, increased 3.1 fold), met protooncogene (Met, increased 4.2 fold), mitogen activated protein kinase 8 (Mapk8, increased 4.7 fold) and Dualspecificity tyrosine-phosphorylation regulated kinase $1 \mathrm{a}$ (Dyrk1a, increased 2.6 fold). The increased expression of these genes indicates a potential compensatory mecha- nism related to the lack of activation of STAT3 or its targets.

\section{STAT3 influences lipid homeostasis in lung type II cells}

Expression of genes encoding sterol regulatory element binding factor 1 and 2 (Srebf1 and Srebf2), their cleavage activating protein (Scap) and multiple SREBP target genes involved in lipid metabolism were decreased in Stat $3^{\Delta / \Delta}$ mice type II cells. As depicted in Figure 1, genes dedicated to the biosynthesis of fatty acid, phospholipid and choles- 


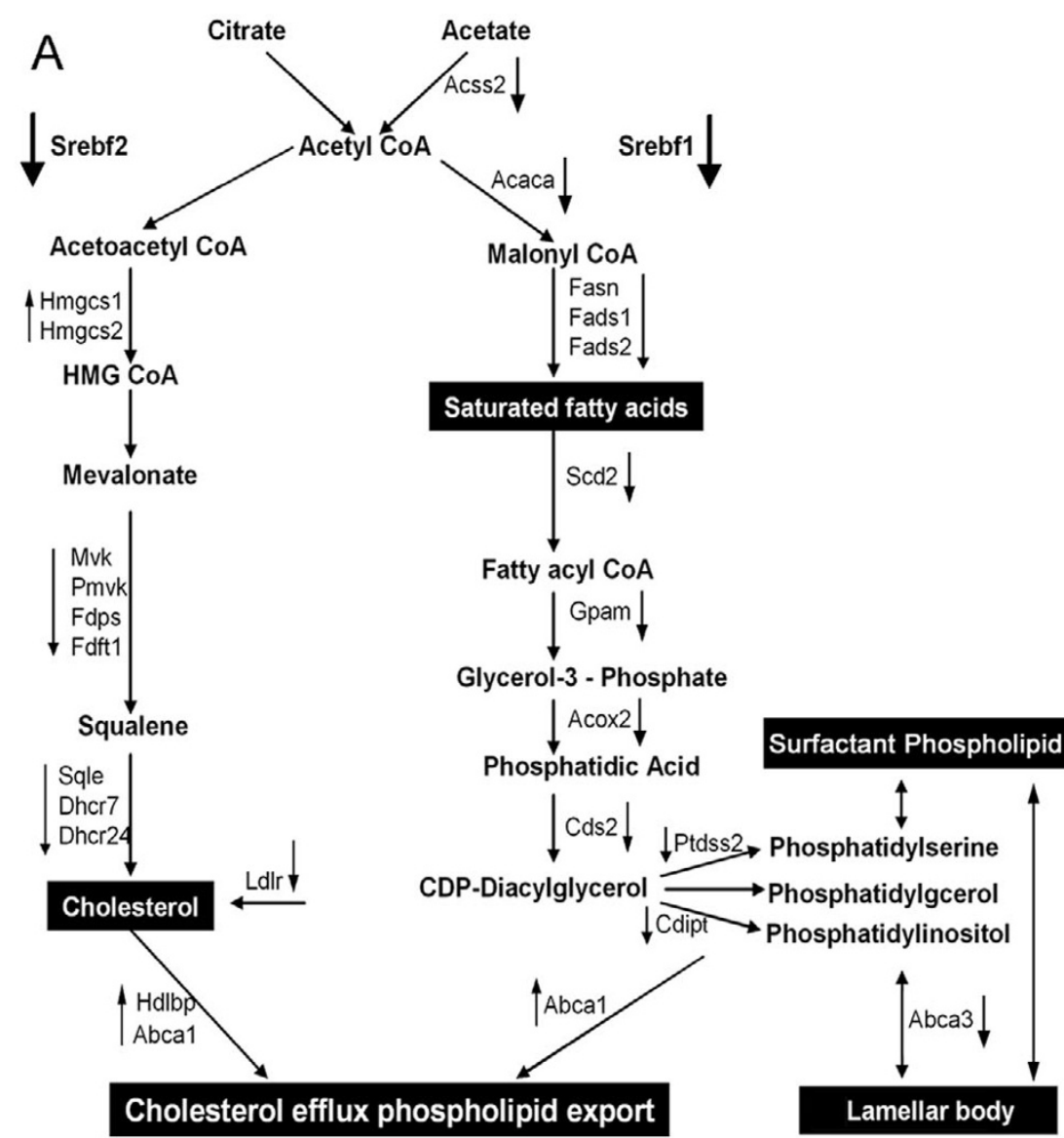

B

\begin{tabular}{l|l|l} 
Symbol & \multicolumn{1}{c|}{ Gene Title } & $\begin{array}{l}\text { Fold } \\
\text { Change }\end{array}$ \\
\hline Acss2 & acyl-CoA synthetase short-chain family member 2 & -3.80 \\
Fads2 & fatty acid desaturase 2 & -2.88 \\
Dhcr24 & 24-dehydrocholesterol reductase & -2.81 \\
Dhcr7 & 7-dehydrocholesterol reductase & -2.23 \\
Fads1 & fatty acid desaturase 1 & -2.19 \\
Fdft1 & farnesyl diphosphate farnesyl transferase 1 & -1.97 \\
Mvk & mevalonate kinase & -1.85 \\
Pmvk & phosphomevalonate kinase & -1.79 \\
Fdps & farnesyl diphosphate synthetase & -1.78 \\
Srebf1 & sterol regulatory element binding factor 1 & -1.73 \\
Cds2 & CDP-diacylglycerol synthase (phosphatidate cytidylyltransfera & -1.72 \\
Acox2 & acyl-Coenzyme A oxidase 2, branched chain & -1.70 \\
Sqle & squalene epoxidase & -1.61 \\
Fasn & fatty acid synthase & -1.61 \\
Ptdss2 & phosphatidylserine synthase 2 & -1.60 \\
Abca3 & ATP-binding cassette, sub-family A (ABC1), member 3 & -1.59 \\
Scd2 & stearoyl-Coenzyme A desaturase 2 & -1.58 \\
Ldlr & Low density lipoprotein receptor & -1.54 \\
Gpam & glycerol-3-phosphate acyltransferase, mitochondrial & -1.54 \\
Cdipt & CDP-diacylglycerol--inositol 3-phosphatidyltransferase & -1.54 \\
Acaca & acetyl-Coenzyme A carboxylase alpha & -1.50 \\
Srebf2 & sterol regulatory element binding factor 2 & -1.50 \\
Hmgcs1 & 3-hydroxy-3-methylglutaryl-Coenzyme A synthase 1 & 1.79 \\
Hmgcs2 & 3-hydroxy-3-methylglutaryl-Coenzyme A synthase 2 & 2.59 \\
Hdllbp & high density lipoprotein (HDL) binding protein & 2.79 \\
Abca1 & ATP-binding cassette, sub-family A (ABC1), member 1 & 2.92 \\
\hline & &
\end{tabular}

\section{Figure I}

Genes involved in lipids biosynthesis and clearance pathways were altered in type II cells from Stat3 ${ }^{\Delta / \Delta}$ mice. A. Srebfl and Srebf2 regulate genes encoding the major metabolic enzymes in the fatty acid, cholesterol and phospholipids biosynthesis. The arrow $(\uparrow)$ indicates that the mRNA level was induced in Stat $3^{\Delta / \Delta}$ mice; $(\downarrow)$ indicates the mRNA level was reduced in Stat $3^{\Delta / \Delta}$ mice. Gene symbols, descriptions and the expression changes are listed in panel B. 
terol were down regulated, with the exception of 3hydroxy-3-methylglutaryl-Coenzyme A synthase (Hmgcs), which was increased. HMGCS participates in other metabolic pathways, including valine, leucine and isoleucine degradation (KEGG 00280). This analysis indicates that metabolic pathways regulating fatty acid, phospholipid, and cholesterol biosynthesis were coordinately decreased after deletion of Stat3 in type II cells, supporting an important role of STAT3 in regulating lipids biosynthesis in the lung. LDL receptor ( $L d l r)$, mediating cholesterol uptake, and ATP-binding cassette A3 (Abca3), important for phospholipid transport, lamellar body formation and pulmonary surfactant secretion in alveolar type II cells were decreased in the Stat $3^{\Delta / \Delta}$ mice cells [36-38]. Recent in vitro studies from our group confirmed the direct binding of SREBP1c to the Abca3 promoter (Besnard et.al, submitted for publication). On the other hand, the increased expression of $A b c a 1$, a key facilitator of cellular cholesterol and phospholipid export $[39,40]$ and high density lipoprotein binding protein (Hdlbp), which may function in the removal of excess cellular cholesterol, suggests that cholesterol and phospholipid clearance were induced after deletion of Stat3. Adenosine kinase $(A d k)$, was increased 8.2 fold. Cellular role of ADK in lipid metabolism is somewhat controversial [41], Adk deficient mice developed neonatal hepatic steatosis and die within 14 days with fatty liver [42]. Increased expression of lipid export genes and decreased expression of genes mediating lipid biosynthesis likely cause a reduction of total lipids level in the type II cells of Stat $3^{\Delta / \Delta}$ mice.

Previous studies demonstrated the susceptibility of $\operatorname{Stat}^{\Delta}{ }^{\Delta /}$ $\Delta$ mice to lung injury and death related to surfactant dysfunction [12]. Consistent with our prediction from the present mRNA microarray analysis, the saturated phosphatidycholine (SatPC) content in bronchoalveolar lavage fluid was significantly decreased in $\operatorname{Stat}^{\Delta / \Delta}$ mice (Figure 2). Significantly decreased SatPC synthesis and abnormalities in lamellar body numbers and morphology were also observed in $\operatorname{Stat}^{\Delta / \Delta}$ mice (data not shown). Taken together, a number of genes regulating surfactant lipid homeostasis were altered in type II cells isolated from the Stat $3^{\Delta / \Delta}$ mice, consistent with biochemical, functional, and morphologic changes in the surfactant system that is exacerbated by oxidant stress [12] or expose to pathogens [13].

\section{Role of Akt in Stat3 regulated lipid metabolism}

Our observations support the view that the decrease in SREBP, at least in part, results in decreased expression of genes regulating lipid biosynthesis and metabolism in type II cells from Stat $3^{\Delta / \Delta}$ mice. SREBPs are master regulators of lipid metabolism. The transcriptional targets, and the pathways mediated by SREBP in liver have been well studied [43]. SREBPs are expressed in the developing lung,

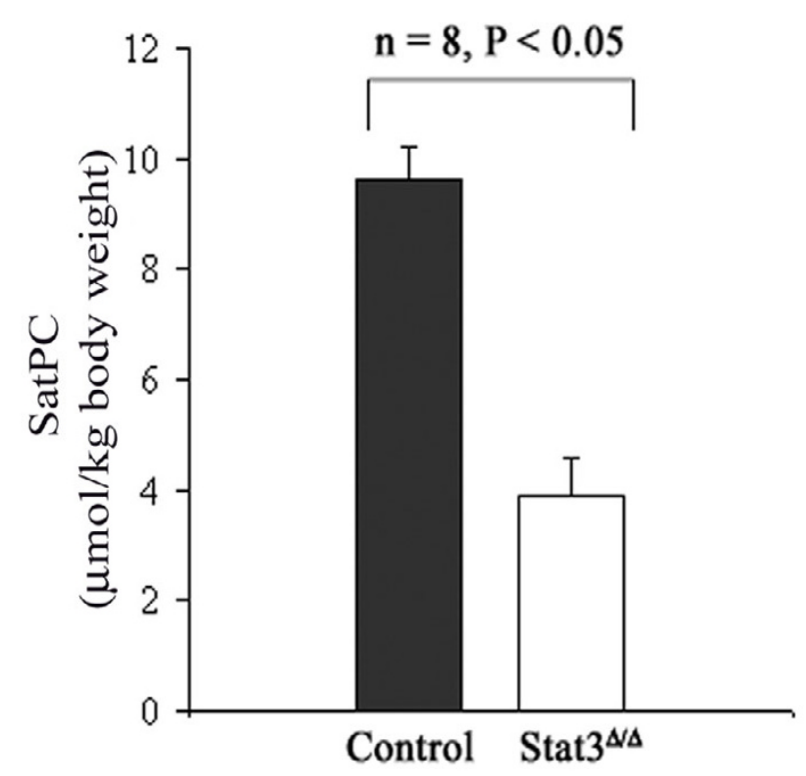

Figure 2

Surfactant saturated phosphatidylcholine (SatPC) was significantly decreased in bronchoalveolar lavage fluid from the Stat $3^{\Delta / \Delta}$ mice, $n=8$ per group. Aliquots of BALF were extracted with chloroform/methanol (2:I) and SatPC was isolated with osmium tetroxide followed by measurement of phosphorus as described previously [12]. Statistical differences were analyzed by Student t-test.

SREB1c increases in the developing lung concomitantly with the perinatal increase in surfactant and lipid synthesis, surfactant protein and Abca3 expression, genes critical for surfactant function.

However, the role of Stat3 in regulating SREBP and associated lipid metabolism in the lung is largely unknown. In the present analysis, we sought to identify mechanisms by which Stat 3 regulates SREBPs and associated lipid biosynthesis pathways in alveolar type II cells in the lung. The regulation of SREBPs occurs at both transcriptional and post-transcriptional levels. The post-transcriptional regulation requires SCAP. Cre-mediated disruption of Scap significantly reduced Srebf1 and 2 levels as well as SREBP target gene expression in liver [44]. There are multiple potential STAT sites on the Scap promoter. Thus, Stat3 may influence lipid biosynthesis through the transcriptional regulation of Scap. At transcriptional level, nuclear hormone receptors (Nr1h2 and Nr1h3) and Pgc1-alpha and beta are known to regulate SREBPs expression in liver. Increased expression of Srebf1 and Fasn was associated with increased hepatic triglyceride content in Stat3 deficient mice $[10,45]$. In the present study, expression of SREBP and their down stream targets were decreased in type II cells from Stat $3^{\Delta / \Delta}$ mice (a finding that contrast 
with the findings in the liver) without changes in other known regulators such as Nr1h2, Nr1h3, Pgc1-alpha or Pgc1-beta, indicating the likely presence of alternative regulatory mechanisms in lung cells.

We hypothesize that AKT plays an important role in Stat3 regulated SREBP expression and associated lipogenesis in lung based on the following observations: 1) Protein and mRNA levels of Akt were increased in cells constitutively expressing active Stat 3 and were reduced after Stat3 depletion [46]. STAT3 binds to Akt1 promoter was confirmed by ChIP assay [47], suggesting that A $k t$ maybe a direct transcriptional target of Stat3. AKT, on the other hand, inhibits Stat3 transcriptional activity and phosphorylation [48]. Decreased Akt gene expression seen after deletion of Stat3 may represent a direct effect of Stat3 deficiency or to a negative regulatory response to STAT3 deficiency, 2) AKT activation induces both Srebf1 and Srebf 2 mRNAs and proteins as well as key enzymes in the cholesterol, fatty acid and membrane lipid biosynthesis pathways [49], 3) Multiple lines of evidence suggest that PI3K influences Stat3 activation. STAT3 binds directly to the PI3K regulatory subunits [50-52]. The expression of genes encoding for several PI3K subunits were altered after deletion of Stat3 (see Additional file 1), supporting the involvement of PI3K/Akt signaling in Stat3 regulated bioprocesses in lung, and 4) Since AKT physically interacts with FOXA2 and regulates FOXA2-dependent transcriptional activity [53], the effects of AKT may be mediated, in part, via Foxa2. Foxa2 expression was reduced more than 2 fold in cells from the Stat $3 \Delta / \Delta$ mice. FOXA2 regulates lipid metabolism in both lung and liver [54,55]. Deletion of either Stat3 or Foxa2 resulting in decreased expression of a number of the overlapping genes that play important roles in surfactant homeostasis including Abca3 [55]. Thus, interactions between AKT and FOXA2 represent another potential mechanism by which lipid metabolism is influenced in $S t a t 3^{\Delta / \Delta}$ mice.

\section{Stat3 influences expression of genes mediating apoptosis and cell survival}

Many genes modulating apoptosis/cell survival were altered in response to the deletion of Stat 3 from type II cells, including multiple Bcl-2 family members ( $B c l 2$, Bcl2l1, Mcl1, Bcl2l11 and Bad), caspase 3 (Casp3), FADDlike apoptosis regulator (Cflar, also known as Flip), mucosa associated lymphoid tissue lymphoma translocation gene 1 (Malt1), prostaglandin-endoperoxide synthase 2 (Ptgs2) and nuclear receptor subfamily 3, group C, member 1 (glucocorticoid receptor, Nr3c1). In depth literature mining identified more apoptosis related genes than did analysis by Gene Ontology annotation. As depicted in Figure 3, our study indicates that STAT3 regulates apoptosis in a complex manner via processes that occur in multiple intracellular locations. Thus, STAT3 appears to serve as key regulator of apoptosis in alveolar type II cells. Among those apoptosis related genes, Malt1, Ptgs 2 and Nr3c1 were strongly induced ( $>5$ fold in compare with control). MALT1 interacts with BCL10 (increased 2 fold in Stat $3 \Delta / \Delta$ mice). The formation of this complex is essential for NFkappaB activation that, in turn, play a role in cell survival. IKKB phosphorylates BCL10 in its MALT1 interaction domain, causing BCL10 and MALT1 to disassociate, resulting in attenuation of NFKB signaling and cytokine production [56,57]. PTGS2 also known as COX-2, a key enzyme in prostaglandin biosynthesis, that is highly expressed in alveolar type II cells. The expression of Ptgs 2 is increased in epithelial tumors, including non-small cell lung and prostate cancers via activation of the IL-6/ GP130/STAT3 signaling pathway [58]. This pathway could contribute to tumor formation by promotion of tumor cell resistance to apoptosis via inhibitor of apoptosis (IAP)-dependent mechanism [58,59]. Consistent with these observations, Ptgs2, Il6st and two of the IAP family members (Birc4 and Birc6) were correspondingly induced in $S t a t 3^{\Delta / \Delta}$ cells $(5.7,1.7,3.2$ and 2.3 fold respectively). $\mathrm{Nr} 3 \mathrm{c} 1$ (increased 5.1 fold) encodes a receptor for glucocorticoids that can act as both a transcription factor and as a regulator of other transcription factors. STAT3 and NR3C1 physically interact to mediate effect of glucocorticoid on the IL-6-mediated inflammatory response [6062]. NR3C1 also interacts with stress-responsive transcription factors (Hif1a, increased 4.7 fold), mitogen activated protein kinase 8 (Mapk8 or Jnk, increased 4.7 fold) and tyrosine 3-monooxygenase/tryptophan 5-monooxygenase activation protein, epsilon polypeptide (Ywhal, increased 3.3 fold), a 14-3-3 family of proteins implicated in the pathogenesis of small cell lung cancer $[63,64]$.

STAT3 is likely to regulate apoptosis by multiple mechanisms including gene transcription. Bcl-xL is the direct transcription target of STAT3[65]. STAT3 can serve as an anti-apoptotic factor by transcriptional up-regulating the expression of Bcl-xL [66]. The decrease of Bcl-xL may represent a direct response to Stat3 deletion. The fact that expression of $\mathrm{Bcl}-\mathrm{xL}$ blocked the apoptotic effects of the adenovirus in lung injury suggested that Bcl-xL may mediate the role of STAT3 in the regulation and survival of the respiratory epithelium [13]. The Pi3k-Akt pathway represents a second mechanism by which STAT3 influences cytoprotection. Pi3k-Akt signaling mediates a wide range of down stream targets to regulate apoptosis [67]. For example, AKT phosphorylates multiple Bcl-2 family members, including BAD and $\mathrm{Bcl}-\mathrm{xL}$ [68], inhibits caspase 3 activation [66] and blocks cytochrome $\mathrm{C}$ release from mitochondria [69]. Another mechanism by which STAT3 modulates apoptosis is through protein-protein interactions. Bcl-xL is a direct transcriptional target of STAT3; Bcl$\mathrm{xL}$ interacts with VDAC1 to regulate the outer mitochondrial membrane channel induce apoptosis [70,71]. 


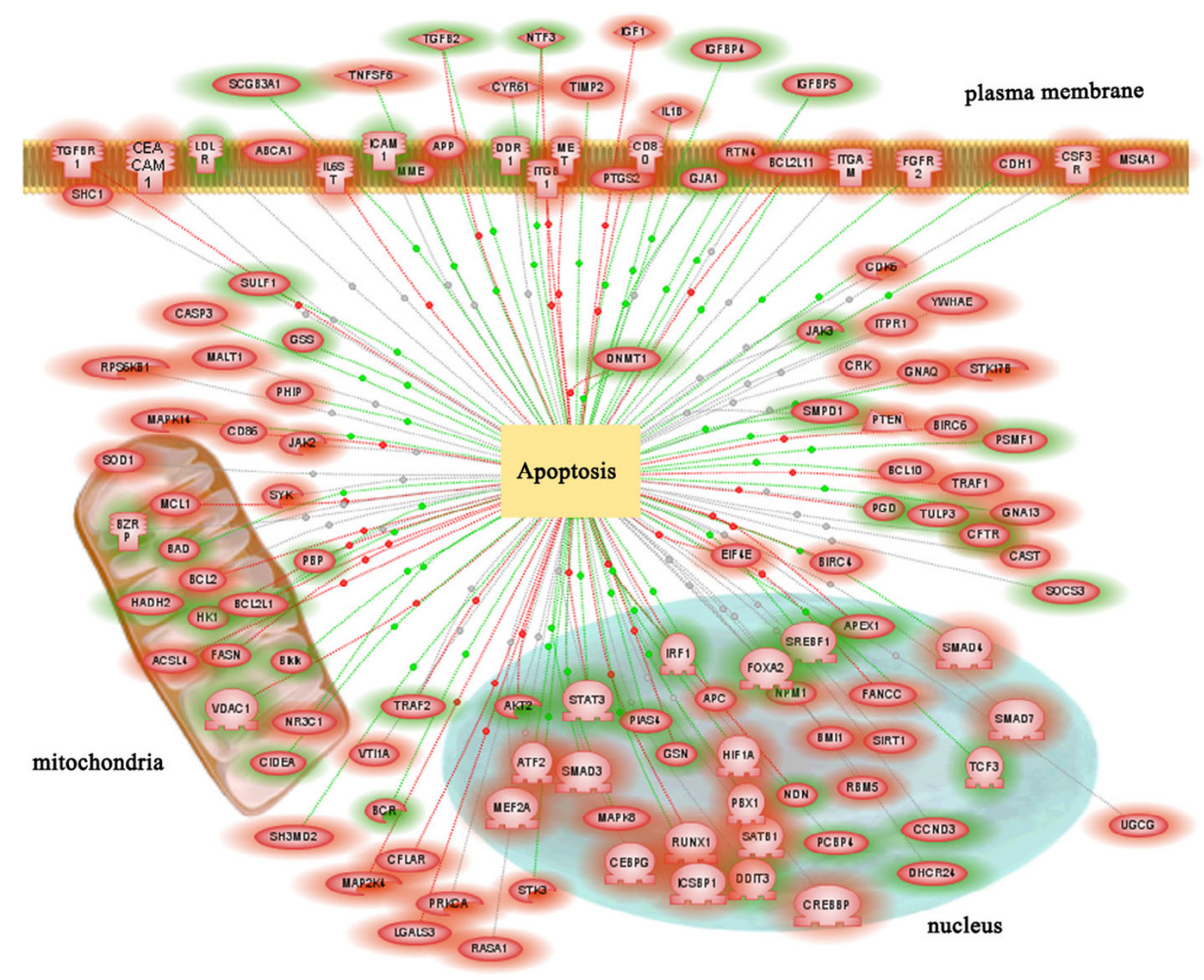

Figure 3

Genes involved in apoptotic pathways were altered in type II cells isolated from Stat3 ${ }^{\Delta / \Delta}$ mice. Genes associated with apoptosis were identified via literature mining using Pathway Studio 4.0 (Ariadne Genomics, Inc.). STAT3 regulates apoptosis positively and negatively, via processes occurring in multiple intracellular compartments. Genes up-regulated in Stat $3^{\Delta / \Delta}$ mice are framed in red. Genes down-regulated in Stat $3 \Delta / \Delta$ mice are framed in green. Each dashed line demarcated with a larger dot linking "apoptosis" and each gene node indicates a regulatory relationship based on the literature references. Regulatory relationships are denoted by line colors (green, positive regulation; red, negative regulation; and gray, regulation direction is unknown).

CASP3 can interact with multiple apoptosis proteins including CFLAR, BIRC4 and 6, BCL2 and APP [72-75]. The expression of Casp3 as well as its interaction partners was induced in Stat $3^{\Delta / \Delta}$ mice. NR3C1 has both pro- and anti-apoptotic effects. NR3C1 physically interact with STAT3, HIF1A, MAPK8, YWHAL [63,64,76]; these stressresponsive transcription factors and signaling molecules were largely induced in the present array from $S t a t 3 \Delta / \Delta$ type II alveolar epithelial cells. The close transcriptional communication and physical interactions among these transcriptional regulators likely play a critical role in regulating the balance of apoptosis and cell survival. In the present study, effects of STAT3 deletion were assessed in type II epithelial cells purified from the adult mouse lung. mRNA was isolated immediately after isolation to avoid cell culture dependent alteration in gene expression. It is possible that the cells have undergone added cellular stress during protease treatment, isolation and purification, which in turn may influence the expression of genes. Our results support the view that STAT3 regulates the balance between a subset of pro- and anti-apoptotic genes, determining the cell death or survival through multiple mechanisms. Consistent with the present microarray prediction, cleaved caspase- 3 and TUNEL positive cells were 
significantly increased in Stat $3^{\Delta / \Delta}$ mice following adenoviral infection and the apoptosis can be blocked by expression of Bcl-xL [13].

\section{Conclusion}

Our previous studies demonstrated that Stat3 plays critical role in cyto-protection during lung injury $[12,13]$. Present data support the role of Stat3 in enhancing epithelial cell survival and surfactant lipid synthesis that contribute to the maintenance of lung function. Deletion of Stat3 from type II alveolar epithelial cells induced the expression of the genes regulating protein metabolism, protein transport, chemotaxis and apoptosis while decreasing the expression of genes regulating lipid synthesis and metabolism. Critical to pulmonary function during injury, Stat3 influences the expression of genes regulating surfactant lipid synthesis and surfactant homeostasis including Abca3. As illustrated in Figure 4, the present study identi- fied a complex regulatory network by which Stat3 regulates gene expression in type II alveolar cells that is required for cellular homeostasis following injury. STAT3 likely interacts with AKT/FOXA2 in the regulation a number of biological processes in alveolar type II cells, including cell survival/apoptosis, cholesterol and fatty acid biosynthesis required for surfactant homeostasis and lung function.

\section{Methods \\ Transgenic Mice}

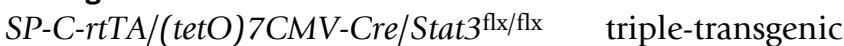
mice were generated as described previously [12]. Stat $3 \mathrm{flx} /$ flx mice were a kind gift of Dr. Takeda (Hyogo College of Medicine, Japan) [8]. In the presence of doxycycline, exon 21 of the Stat3 gene is permanently deleted from respiratory epithelial cells prior to birth (Stat $3^{\Delta / \Delta}$ mice) [12]. Stat3 deleted transgenic $\left(\operatorname{Stat}^{\Delta / \Delta}\right)$ and non-deleted litter-

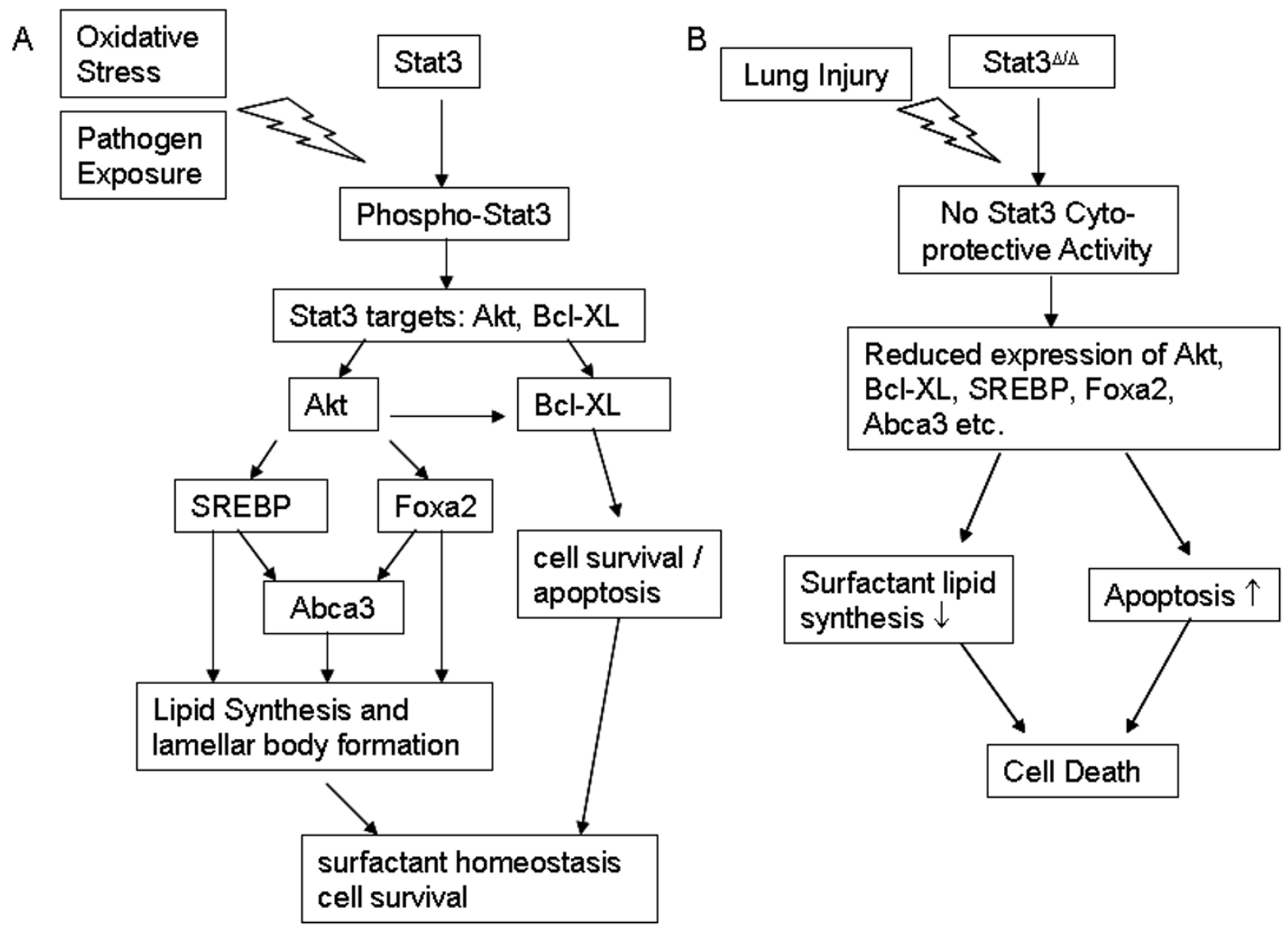

\section{Figure 4}

Schematic representation of the proposed role of Stat3 in cytoprotection of the lung in normal (A) versus Stat3 ${ }^{\Delta / \Delta}$ mice (B). Stat3 plays critical role in cyto-protection during lung injury [12, I3]. Present data support the role of Stat3 in enhancing epithelial cell survival and surfactant lipid synthesis that contribute to the maintenance of lung function. For simplicity, only representative genes were included. 
mates (double transgenic,SP-C-rtTA, or tetO7CMV-Cre and $S \operatorname{tat} 3^{\mathrm{flx} / \mathrm{flx}}$ ) were used for the experiments. Doxycycline was administered to the dams in the food at a concentration of $625 \mathrm{mg} / \mathrm{kg}$ (Harlan Teklad, Madison, WI) from embryonic day 0 (E0) to postnatal day 25 (P25), resulting in extensive deletion of Stat3 in respiratory epithelial cells [12]. As previously described, deletion of Stat3 did not alter lung size, morphology or survival under non-stressed condition [13].

\section{RNA Extraction}

Alveolar type II cells were isolated from 8 weeks old, sex and age matched littermate control and $\operatorname{Stat}^{\Delta / \Delta}$ mice using collagenase and differential plating as described by Rice et al.[77]. Type II cells from 3 mice were pooled to obtain one cell pellet. Three independent pools were generated from control and Stat $3^{\Delta / \Delta}$ mice separately for purification of RNA and microarray hybridization. Type II cells were homogenized with TRIzol reagent (Invitrogen, Carlsbad, CA). RNA concentration was measured by spectrophotometer and normalized prior to cDNA synthesis. These cell isolates consist of more than 90\% alveolar type II cells with residual alveolar macrophages as the major contaminating cell. Purity was assessed by modified Papanicolaou stain. Purity and number of type II cells isolated from Stat $3^{\Delta / \Delta}$ mice were not different from controls.

\section{RNA Microarray Analysis}

mRNA was extracted from three independent pools of isolated type II cells from adult Stat $3^{\Delta / \Delta}$ and control mice. The cRNA was then hybridized to the murine genome MOE430 (consists of $\approx 45000$ gene entries) chips (Affymetrix, Santa Clara, CA) according to the manufacturer's protocol. The RNA quality and quantity assessment, probe preparation, labeling, hybridization and image scan were carried out in the CCHMC Affymetrix Core using standard procedure. RNA quality and quantity were analyzed by spectrophotometer. The A260/A280 ratio was used to determine RNA purity with the acceptable region of 1.9-2.1. Affymetrix Microarray Suite 5.0 was used to scan and quantitate the gene chips under default scan settings. Normalization was performed using the Robust Multichip Average model [78,79]. Data were further analyzed using affylmGUI from R/Bioconductor package [80]. Differentially expressed genes were selected with the threshold of T-Test P-value $\leq 0.05$, False Discovery Rate $(F D R) \leq 10 \%$ and fold change $\geq 1.5$. We prioritized the mRNAs whose abundance consistently changed in multiple probe sets by selecting them without the FDR consideration. Unknown cDNA clones/ESTs and duplicated gene entries were removed from further functional analysis.

\section{Gene Ontology Analysis}

Gene Ontology Analysis was performed using public available web-based tool David (database for annotation, visualization, and integrated discovery) [81]. Overrepresented biological processes were selected at the threshold of Fisher Exact Test P-Value $\leq 0.05$ and minimum gene counts belonging to an annotation term $\geq 2 \%$.

\section{Promoter Analysis: Transcription Factor Binding Sites Search}

Promoter sequences of all differentially expressed genes (2000 bp upstream from the tentative TSS) were retrieved from our database (originally downloaded from UCSC Genome browser) and searched for over-represented TFBS (Transcription Factor Binding Site) in these sequences using MatInspector (Genomatix) using the complete Vertebrate Matrix Library 6.2. The P value is calculated using binomial distribution probability by comparing the matrix match of the promoter regions of differentially expressed genes with the promoters from random mouse genes sets ( $-2 \mathrm{~kb}$ for all the promoters). The single-step Bonferroni adjustment is used to control for the multiple comparison effect (i.e., multiplication of p-value by the number of TFBS in Genomatix Vertebrate Matrix Library).

\section{Pathway Enrichment Test}

Overrepresented pathways were identified by comparison the overlap of differentially expressed genes and all genes in MOE430 mouse genome (reference) with the known KEGG pathways. A Fisher's exact test for $2 \cdot 2$ contingency table was used to calculate the statistical significance. A pathway is considered to be over-represented when a probability $\mathrm{P}$ value $=0.01$ and gene frequency (genes in the pathway/total number of differentially expressed genes) $\geq 2 \%$.

\section{Literature Mining}

Potential protein-protein or protein-DNA interactions were identified using Pathway Studio (Ariadne Genomics) that contains MedScan, an automated text-mining tool to search the entire PubMed and other public sources (The current version database contains more than 15 million Medline abstracts/full text). Gene expression profiling results was imported into the Studio and used to interpret pathways, gene regulation networks, and protein interaction maps.

\section{Validation of mRNAs}

Real-time RT-PCR was used to cross validate changes in a subset of genes from microarray selection. mRNA was extracted from alveolar type II epithelial cells isolated from $S t a t 3^{\Delta / \Delta}$ and control mice using RNeasy Protect mini kit (Qiagen, Valencia, CA) according to the manufacturer's protocol. RNA concentration was measured by spectrophotometer. cDNA was made with SuperScript 
First-Strand Synthesis System (Invitrogen, Carlsbad, CA). Malt1, Rtn4, Reg3g, Bcl2l1, Abca3, Scap, Fasn, Srebf1 and Srebf2 were detected using primers listed Changes in mRNA were determined in type II cells isolated from Stat $3^{\Delta / \Delta}$ and controls ( $n=3-4 /$ group). The following primers were used: Malt1: forward, TAT CCA GGA GGA CCC CAT GT and reverse, TCT GAT CAA AGC CAG TTA GCA TCAT; Rtn4: forward, AAG TGG AAG GAG TTT GAG AGA GCA and reverse, CTG TCT CAA AGC AGA TGT GAA AGC; Reg3g: forward, TGC CAA AAG AGC CCT CAG GA and reverse, TGC CTG AGG AAG AGG AAG GAT TCG; Bcl2l1: forward, TCT CTC TCC TCT GTC CAC CCT TG and reverse, TGC CCC TCA GAA GCC AGA AC; Abca3: forward, GCA TTG CCC TCA TTG GAG AGC CTG and reverse, TCC GGC CAT CCT CAG TGG TGG G; Scap: forward, TGA CCA CAA ACA AGG AGA GC and reverse, CAG GAA CAC CAA ACA GCA AG; Srebf1: forward, AAG CCG GGT GGG CGC CGG CGC CAT and reverse, GTC GTT CAA AAC CGC TGT GTC CAG; Srebf2: forward, CAT CCA GCA GCC TTT GAT ATA CCA G and reverse, AGG ACC GGG ACC TGC TGC ACC TGT G. Fasn: forward, GGA CAT GGT CAC AGA CGA TGA C and reverse, GTC GAA CTT GGA CAG ATC CTT CA. The PCR product was separated by the $1 \%$ agarose gel electrophoresis. $\beta$-actin was used as the internal control. Taqman Gene Expression Assay were used to confirm the expression of Akt2, Cdipt, Acox2, Cds2 and Gpam using Applied Biosystems 7300 Real-Time PCR System and company designed probes (Applied Biosystems). Statistical differences were determined using unpaired Student's t-tests.

\section{Additional material}

\section{Additional file 1}

Genes Differentially Expressed in Stat $3^{\Delta / \Delta}$ Mice. Additional file descriptions text (including details of how to view the file, if it is in a non-standard format).

Click here for file

[http://www.biomedcentral.com/content/supplementary/14712164-8-455-S1.doc]

\section{Additional file 2}

Differentially Expressed Genes In Jak-Stat, Insulin and Wnt Signaling Pathway. Pathways were downloaded from KEGG website [82]. Each rectangle represents one or multiple gene products. Genes up-regulated in Stat $3^{\Delta / \Delta}$ mice are highlighted in red. Genes down-regulated in Stat $3^{4 / \Delta}$ mice are highlighted in blue. Rectangle contains more than one gene products and changes expression in opposite directions are highlighted in yellow.

Click here for file

[http://www.biomedcentral.com/content/supplementary/14712164-8-455-S2.doc]

\section{Acknowledgements}

We thank Ann Maher for secretarial assistance, Valerie Besnard for scientific discussion. We also thank Dr. K. Takeda (Hyogo College of Medicine) for the gift of Stat3flx/flx mice.

This work was supported by National Institutes of Health Grant HL6I646 to M. Ikegami, Y. Xu and J.A. Whitsett.

\section{References}

I. Zhong Z, Wen Z, Darnell JE Jr: Stat3: a STAT family member activated by tyrosine phosphorylation in response to epidermal growth factor and interleukin-6. Science 1994, 264(5 I 55):95-98.

2. Decker T, Kovarik P: Serine phosphorylation of STATs. Oncogene 2000, I 9(2I):2628-2637.

3. Takeda K, Akira S: STAT family of transcription factors in cytokine-mediated biological responses. Cytokine Growth Factor Rev 2000, II(3): 199-207.

4. Hirano T, Ishihara K, Hibi M: Roles of STAT3 in mediating the cell growth, differentiation and survival signals relayed through the IL-6 family of cytokine receptors. Oncogene 2000, 19(2I):2548-2556.

5. Levy DE, Lee CK: What does Stat3 do? J Clin Invest 2002, I09(9): I | 433-1 | 48 .

6. Yang J, Liao X, Agarwal MK, Barnes L, Auron PE, Stark GR: Unphosphorylated STAT3 accumulates in response to IL- 6 and activates transcription by binding to NFkappaB. Genes \& development 2007, 2 I (I I): 1396-1408.

7. Inghirami G, Chiarle R, Simmons WJ, Piva R, Schlessinger K, Levy DE: New and old functions of STAT3: a pivotal target for individualized treatment of cancer. Cell Cycle 2005, 4(9): | I3 |- | | 33.

8. Leeman RJ, Lui VW, Grandis JR: STAT3 as a therapeutic target in head and neck cancer. Expert Opin Biol Ther 2006, 6(3):23I-24I.

9. Takeda K, Noguchi K, Shi W, Tanaka T, Matsumoto M, Yoshida N, Kishimoto T, Akira S: Targeted disruption of the mouse Stat3 gene leads to early embryonic lethality. Proc Natl Acad Sci USA 1997, 94(8):380I-3804.

10. Jacoby J], Kalinowski A, Liu MG, Zhang SS, Gao O, Chai GX, Ji L, Iwamoto Y, Li E, Schneider M, et al:: Cardiomyocyte-restricted knockout of STAT3 results in higher sensitivity to inflammation, cardiac fibrosis, and heart failure with advanced age. Proc Natl Acad Sci USA 2003, I 00(22): 12929- 12934.

II. Inoue $\mathrm{H}$, Ogawa $\mathrm{W}$, Ozaki M, Haga S, Matsumoto M, Furukawa $\mathrm{K}$, Hashimoto N, Kido Y, Mori T, Sakaue H, Teshigawara K, Jin S, Iguchi H, Hiramatsu R, LeRoith D, Takeda K, Akira S, Kasuga M: Role of STAT-3 in regulation of hepatic gluconeogenic genes and carbohydrate metabolism in vivo. Nat Med 2004, I0(2): 168-174.

12. Hokuto I, Ikegami M, Yoshida M, Takeda K, Akira S, Perl AK, Hull WM, Wert SE, Whitsett JA: Stat-3 is required for pulmonary homeostasis during hyperoxia. J Clin Invest 2004, I I 3(I):28-37.

13. Matsuzaki $Y, X u$ Y, lkegami M, Besnard V, Park KS, Hull WM, Wert $\mathrm{SE}$, Whitsett JA: Stat 3 is required for cytoprotection of the respiratory epithelium during adenoviral infection. J Immunol 2006, I77(I):527-537.

14. Lian X, Qin Y, Hossain SA, Yang L, White A, Xu H, Shipley JM, Li T, Senior RM, Du H, Yan C: Overexpression of Stat3C in pulmonary epithelium protects against hyperoxic lung injury. J Immunol 2005, I74(II):7250-7256.

15. Chapman RS, Lourenco PC, Tonner E, Flint DJ, Selbert S, Takeda K, Akira S, Clarke AR, Watson CJ: Suppression of epithelial apoptosis and delayed mammary gland involution in mice with a conditional knockout of Stat3. Genes Dev 1999, I3(19):2604-26I6.

16. Ng DC, Lin BH, Lim CP, Huang G, Zhang T, Poli V, Cao X: Stat3 regulates microtubules by antagonizing the depolymerization activity of stathmin. J Cell Biol 2006, I 72(2):245-257.

17. Gene Expression Omnibus (GEO) Main Page [http:// www.ncbi.nlm.nih.gov/geo/]

18. Cantwell CA, Sterneck E, Johnson PF: Interleukin-6-specific activation of the C/EBPdelta gene in hepatocytes is mediated by Stat3 and SpI. Mol Cell Biol I998, 18(4):2108-2II7. 
19. Sanchez-Elsner T, Botella LM, Velasco B, Corbi A, Attisano L, Bernabeu C: Synergistic Cooperation between Hypoxia and Transforming Growth Factor-beta Pathways on Human Vascular Endothelial Growth Factor Gene Expression. J Biol Chem 200I, 276(42):38527-38535.

20. Sanchez-Elsner T, Ramirez JR, Sanz-Rodriguez F, Varela E, Bernabeu C, Botella LM: A cross-talk between hypoxia and TGF-beta orchestrates erythropoietin gene regulation through SPI and Smads. J Mol Biol 2004, 336(I):9-24.

21. Karlseder J, Rotheneder H, Wintersberger E: Interaction of Sp I with the growth- and cell cycle-regulated transcription factor E2F. Mol Cell Biol 1996, 16(4):1659-1667.

22. Sanjay A, Horne WC, Baron R: The Cbl family: ubiquitin ligases regulating signaling by tyrosine kinases. SCi STKE 200I, 200I(I I0):PE40.

23. Dinudom A, Harvey KF, Komwatana P, Young JA, Kumar S, Cook DI: Nedd4 mediates control of an epithelial $\mathrm{Na}+$ channel in salivary duct cells by cytosolic Na+. Proc Natl Acad Sci USA 1998, 95(I2):7169-7|73.

24. Fang D, Liu YC: Proteolysis-independent regulation of PI3K by Cbl-b-mediated ubiquitination in T cells. Nat Immunol 2001 2(9):870-875

25. Liu YC, Altman A: Cbl: complex formation and functional implications. Cell Signal 1998, 10(6):377-385.

26. Deckert M, Elly C, Altman A, Liu YC: Coordinated regulation of the tyrosine phosphorylation of $\mathrm{Cbl}$ by Fyn and Syk tyrosine kinases. J Biol Chem 1998, 273( (15):8867-8874.

27. Liu J, DeYoung SM, Hwang JB, O'Leary EE, Saltiel AR: The roles of Cbl-b and c-Cbl in insulin-stimulated glucose transport. J Biol Chem 2003, 278(38):36754-36762.

28. Magnifico A, Ettenberg S, Yang C, Mariano J, Tiwari S, Fang S, Lipkowitz S, Weissman AM: WW domain HECT E3s target CbI RING finger E3s for proteasomal degradation. J Biol Chem 2003, 278(44):43|69-43|77.

29. Ungureanu D, Silvennoinen O: SLIM trims STATs: ubiquitin E3 ligases provide insights for specificity in the regulation of cytokine signaling. SCi STKE 2005, 2005(304):pe49.

30. Le Drean Y, Mincheneau N, Le Goff P, Michel D: Potentiation of glucocorticoid receptor transcriptional activity by sumoylation. Endocrinology 2002, I 43(9):3482-3489.

31. Heinrich PC, Behrmann I, Muller-Newen G, Schaper F, Graeve L Interleukin-6-type cytokine signalling through the gp /30/Jak/ STAT pathway. Biochem J 1998, 334(Pt 2):297-3।4.

32. Matsuo R, Ochiai $W$, Nakashima K, Taga T: A new expression cloning strategy for isolation of substrate-specific kinases by using phosphorylation site-specific antibody. J Immunol Methods 200I, 247(I-2):|4|-|5|.

33. Zhang Y, Cho YY, Petersen BL, Bode AM, Zhu F, Dong Z: Ataxia telangiectasia mutated proteins, MAPKs, and RSK2 are involved in the phosphorylation of STAT3. J Biol Chem 2003, 278(I 5): I 2650-12659.

34. Yuan ZL, Guan YJ, Wang L, Wei W, Kane AB, Chin YE: Central role of the threonine residue within the $\mathrm{p}+\mathrm{I}$ loop of receptor tyrosine kinase in STAT3 constitutive phosphorylation in metastatic cancer cells. Mol Cell Biol 2004, 24(2I):9390-9400.

35. Lo RK, Wise $\mathrm{H}$, Wong $\mathrm{YH}$ : Prostacyclin receptor induces STATI and STAT3 phosphorylations in human erythroleukemia cells: a mechanism requiring PTX-insensitive G proteins, ERK and JNK. Cell Signal 2006, I8(3):307-3I7.

36. Loeffler B, Heeren J, Blaeser M, Radner H, Kayser D, Aydin B, Merkel M: Lipoprotein lipase facilitated uptake of LDL is mediated by the LDL receptor. J Lipid Res 2006.

37. Whitsett JA: Genetic disorders of surfactant homeostasis. Paediatr Respir Rev 2006, 7(SuppI I):S240-242.

38. Fitzgerald ML, Xavier R, Haley KJ, Welti R, Goss JL, Brown CE, Zhuang DZ, Bell SA, Lu N, McKee M, Seed B, Freeman MW: ABCA3 inactivation in mice causes respiratory failure, loss of pulmonary surfactant, and depletion of lung phosphatidylglycerol. J Lipid Res 2007, 48(3):62।-632.

39. Fitzgerald ML, Morris AL, Chroni A, Mendez AJ, Zannis VI, Freeman MW: ABCAI and amphipathic apolipoproteins form highaffinity molecular complexes required for cholesterol efflux. J Lipid Res 2004, 45(2):287-294.

40. Wang N, Silver DL, Costet P, Tall AR: Specific binding of ApoA-I, enhanced cholesterol efflux, and altered plasma membrane morphology in cells expressing ABCI. I Biol Chem 2000, 275(42):33053-33058

4I. Kather H: Pathways of purine metabolism in human adipocytes. Further evidence against a role of adenosine as an endogenous regulator of human fat cell function. J Biol Chem 1990, 265(I):96-102.

42. Boison D, Scheurer L, Zumsteg V, Rulicke T, Litynski P, Fowler B, Brandner S, Mohler H: Neonatal hepatic steatosis by disruption of the adenosine kinase gene. Proc Natl Acad Sci USA 2002, 99( I 0):6985-6990.

43. Horton JD, Goldstein JL, Brown MS: SREBPs: activators of the complete program of cholesterol and fatty acid synthesis in the liver. J Clin Invest 2002, 109(9): I I25- I I 3 I.

44. Matsuda M, Korn BS, Hammer RE, Moon YA, Komuro R, Horton JD, Goldstein JL, Brown MS, Shimomura I: SREBP cleavage-activating protein (SCAP) is required for increased lipid synthesis in liver induced by cholesterol deprivation and insulin elevation. Genes Dev 200I, I 5(I 0):1206-1216.

45. Lin J, Yang R, Tarr PT, Wu PH, Handschin C, Li S, Yang W, Pei L, Uldry M, Tontonoz P, Newgard CB, Spiegelman BM: Hyperlipidemic effects of dietary saturated fats mediated through PGCI beta coactivation of SREBP. Cell 2005, I 20(2):26I-273.

46. Park S, Kim D, Kaneko S, Szewczyk KM, Nicosia SV, Yu H, Jove R, Cheng JQ: Molecular cloning and characterization of the human AKTI promoter uncovers its up-regulation by the Src/Stat3 pathway. J Biol Chem 2005, 280(47):38932-3894I.

47. Xu Q, Briggs J, Park S, Niu G, Kortylewski M, Zhang S, Gritsko T, Turkson J, Kay H, Semenza GL, Cheng JQ, Jove R, Yu H: Targeting Stat3 blocks both HIF-I and VEGF expression induced by multiple oncogenic growth signaling pathways. Oncogene 2005, 24(36):5552-5560.

48. Barre B, Avril S, Coqueret O: Opposite regulation of myc and p2 I wafl transcription by STAT3 proteins. J Biol Chem 2003, 278(5):2990-2996

49. Porstmann T, Griffiths B, Chung YL, Delpuech O, Griffiths JR, Downward J, Schulze A: PKB/Akt induces transcription of enzymes involved in cholesterol and fatty acid biosynthesis via activation of SREBP. Oncogene 2005, 24(43):6465-648I.

50. Abell K, Watson CJ: The Jak/Stat pathway: a novel way to regulate PI3K activity. Cell Cycle 2005, 4(7):897-900.

51. Abell K, Bilancio A, Clarkson RW, Tiffen PG, Altaparmakov Al, Burdon TG, Asano T, Vanhaesebroeck B, Watson CI: Stat3-induced apoptosis requires a molecular switch in $\mathrm{PI}(3) \mathrm{K}$ subunit composition. Nat Cell Biol 2005, 7(4):392-398.

52. Liu AM, Lo RK, Wong CS, Morris C, Wise H, Wong $\mathrm{YH}$ : Activation of STAT3 by $\mathbf{G}$ alpha(s) distinctively requires protein kinase A, JNK, and phosphatidylinositol 3-kinase. J Biol Chem 2006, 28 I (47):358|2-35825.

53. Wolfrum C, Besser D, Luca E, Stoffel M: Insulin regulates the activity of forkhead transcription factor Hnf-3beta/Foxa-2 by Akt-mediated phosphorylation and nuclear/cytosolic localization. Proc Natl Acad Sci USA 2003, I00(20): I I624-I I 629.

54. Wolfrum C, Asilmaz E, Luca E, Friedman JM, Stoffel M: Foxa2 regulates lipid metabolism and ketogenesis in the liver during fasting and in diabetes. Nature 2004, 432(7020): $1027-1032$

55. Wan $\mathrm{H}, \mathrm{Xu}$ Y, lkegami M, Stahlman MT, Kaestner KH, Ang SL, Whitsett JA: Foxa2 is required for transition to air breathing at birth. Proc Natl Acad Sci USA 2004, I 0 I (40): I 4449- I 4454

56. Ruefli-Brasse AA, French DM, Dixit VM: Regulation of NF-kappaB-dependent lymphocyte activation and development by paracaspase. Science 2003, 302(5650): | 58|-| 584.

57. Wegener E, Oeckinghaus A, Papadopoulou N, Lavitas L, Schmidt-Supprian M, Ferch U, Mak TW, Ruland J, Heissmeyer V, Krappmann D: Essential role for IkappaB kinase beta in remodeling Carmal-Bcll 0-MaltI complexes upon T cell activation. Mol Cell 2006, 23(I): 13-23

58. Dalwadi H, Krysan K, Heuze-Vourc'h N, Dohadwala M, Elashoff $D$, Sharma S, Cacalano N, Lichtenstein A, Dubinett S: Cyclooxygenase-2-dependent activation of signal transducer and activator of transcription 3 by interleukin-6 in non-small cell lung cancer. Clin Cancer Res 2005, I I (2I):7674-7682.

59. Liu XH, Kirschenbaum A, Lu M, Yao S, Klausner A, Preston C, Holland JF, Levine AC: Prostaglandin E(2) stimulates prostatic intraepithelial neoplasia cell growth through activation of the interleukin-6/GP I30/STAT-3 signaling pathway. Biochem Biophys Res Commun 2002, 290(1):249-255. 
60. Yoo JY, Wang W, Desiderio S, Nathans D: Synergistic activity of STAT3 and c-Jun at a specific array of DNA elements in the alpha 2-macroglobulin promoter. I Biol Chem 200I, 276(28):2642I-26429.

61. Kordula T, Travis J: The role of Stat and C/EBP transcription factors in the synergistic activation of rat serine protease inhibitor-3 gene by interleukin- 6 and dexamethasone. Biochem J 1996, 3 I3(Pt 3): 1019-1027.

62. Zhang Z, Jones S, Hagood JS, Fuentes NL, Fuller GM: STAT3 acts as a co-activator of glucocorticoid receptor signaling. J Biol Chem 1997, 272(49):30607-306I0.

63. Konishi H, Nakagawa T, Harano T, Mizuno K, Saito H, Masuda A, Matsuda $H$, Osada $H$, Takahashi T: Identification of frequent $\mathbf{G ( 2 )}$ checkpoint impairment and a homozygous deletion of 14-33 epsilon at I7p/3.3 in small cell lung cancers. Cancer Res 2002, 62(I):27I-276.

64. Kino T, Souvatzoglou E, De Martino MU, Tsopanomihalu M, Wan Y, Chrousos GP: Protein 14-3-3sigma interacts with and favors cytoplasmic subcellular localization of the glucocorticoid receptor, acting as a negative regulator of the glucocorticoid signaling pathway. J Biol Chem 2003, 278(28):2565I-25656.

65. Bromberg JF, Wrzeszczynska MH, Devgan G, Zhao Y, Pestell RG, Albanese C, Darnell JE Jr: Stat3 as an oncogene. Cell 1999, 98(3):295-303.

66. Alas S, Bonavida B: Rituximab inactivates signal transducer and activation of transcription 3 (STAT3) activity in B-nonHodgkin's lymphoma through inhibition of the interleukin 10 autocrine/paracrine loop and results in down-regulation of Bcl-2 and sensitization to cytotoxic drugs. Cancer Res 200I, 6I(13):5I37-5I44.

67. Datta SR, Brunet A, Greenberg ME: Cellular survival: a play in three Akts. Genes Dev 1999, 13(22):2905-2927.

68. Jones RG, Parsons M, Bonnard M, Chan VS, Yeh WC, Woodgett JR, Ohashi PS: Protein kinase B regulates T lymphocyte survival, nuclear factor kappaB activation, and $\mathrm{Bcl}-\mathbf{X}(\mathrm{L})$ levels in vivo. J Exp Med 2000, 19 I (I0): $1721-1734$.

69. Juin P, Hueber AO, Littlewood T, Evan G: c-Myc-induced sensitization to apoptosis is mediated through cytochrome c release. Genes Dev 1999, I3(II):|367-1381.

70. Kadoya T, Yamamoto H, Suzuki T, Yukita A, Fukui A, Michiue T, Asahara T, Tanaka K, Asashima M, Kikuchi A: Desumoylation activity of Axam, a novel Axin-binding protein, is involved in downregulation of beta-catenin. Mol Cell Biol 2002, 22(I I):3803-38I9.

7I. Hammond PW, Alpin J, Rise CE, Wright M, Kreider BL: In vitro selection and characterization of $\mathrm{Bcl}-\mathrm{X}(\mathrm{L})$-binding proteins from a mix of tissue-specific mRNA display libraries. J Biol Chem 200I, 276(24):20898-20906.

72. Uetsuki T, Takemoto K, Nishimura I, Okamoto M, Niinobe M, Momoi $\mathrm{T}$, Miura M, Yoshikawa K: Activation of neuronal caspase-3 by intracellular accumulation of wild-type Alzheimer amyloid precursor protein. I Neurosci 1999, I 9(16):6955-6964.

73. Nishimura I, Uetsuki T, Kuwako K, Hara T, Kawakami T, Aimoto S, Yoshikawa K: Cell death induced by a caspase-cleaved transmembrane fragment of the Alzheimer amyloid precursor protein. Cell Death Differ 2002, 9(2): 199-208.

74. Scott FL, Denault JB, Riedl SJ, Shin H, Renatus M, Salvesen GS: XIAP inhibits caspase-3 and $\mathbf{- 7}$ using two binding sites: evolutionarily conserved mechanism of IAPs. Embo J 2005, 24(3):645-655.

75. Shu HB, Halpin DR, Goeddel DV: Casper is a FADD- and caspase-related inducer of apoptosis. Immunity 1997, 6(6):75I-763.

76. Bruna A, Nicolas M, Munoz A, Kyriakis JM, Caelles C: Glucocorticoid receptor-JNK interaction mediates inhibition of the JNK pathway by glucocorticoids. Embo J 2003, 22(22):6035-6044.

77. Rice WR, Conkright JJ, Na CL, Ikegami M, Shannon JM, Weaver TE: Maintenance of the mouse type II cell phenotype in vitro. Am J Physiol Lung Cell Mol Physiol 2002, 283(2):L256-264.

78. Irizarry RA, Hobbs B, Collin F, Beazer-Barclay YD, Antonellis KJ, Scherf U, Speed TP: Exploration, normalization, and summaries of high density oligonucleotide array probe level data. Biostatistics 2003, 4(2):249-264.

79. Irizarry RA, Bolstad BM, Collin F, Cope LM, Hobbs B, Speed TP: Summaries of Affymetrix GeneChip probe level data. Nucleic Acids Res 2003, 3 I (4):el5.

80. Smyth GK: Linear models and empirical bayes methods for assessing differential expression in microarray experiments.
Statistical applications in genetics and molecular biology Bioconductor 2004, 3:Article3 [http://bioconductor.org/].

8I. Dennis G Jr, Sherman BT, Hosack DA, Yang J, Gao W, Lane HC, Lempicki RA: DAVID: Database for Annotation, Visualization, and Integrated Discovery. Genome Biol DAVID 2003, 4(5P3 [http:// david.abcc.ncifcrf.gov/home.jsp].

82. KEGG [http://www.genome.ad.jp/kegg/]
Publish with Bio Med Central and every scientist can read your work free of charge

"BioMed Central will be the most significant development for disseminating the results of biomedical research in our lifetime. "

Sir Paul Nurse, Cancer Research UK

Your research papers will be:

- available free of charge to the entire biomedical community

- peer reviewed and published immediately upon acceptance

- cited in PubMed and archived on PubMed Central

- yours - you keep the copyright

Submit your manuscript here:

http://www.biomedcentral.com/info/publishing_adv.asp
BioMedcentral 